\title{
Real-world experience of ocrelizumab in multiple sclerosis patients in Latin America
}

\section{Experiencia en la vida real con el uso de ocrelizumab en pacientes con esclerosis múltiple en Latinoamérica}

\author{
Juan Ignacio ROJAS',2, Liliana PATRUCCO ${ }^{2,3}$, Manuel FRUNS ${ }^{4}$, Giesela HORNUNG 4 , José FLORES 5,6, \\ Edgar CARNERO CONTENTTI', Pablo Adrian LOPEZ', Juan Pablo PETTINICCHI', Alejandro CARIDE', \\ Lorna GALLEGUILLOS ${ }^{8}$, Jorge BARAHONA ${ }^{8}$, Violeta DIAZ, Marianella HERNÁNDEZ ${ }^{8}$, Ricardo ALONSO 9,10 , \\ Edgardo CRISTIANO²
}

\begin{abstract}
Background: Despite the abundance of information concerning ocrelizumab in phase III clinical trials, there is scarce evidence regarding real-world patient profiles. Objective: The aim of this study was to investigate patient profiles, effectiveness and persistence with treatment among patients who used ocrelizumab for treatment of multiple sclerosis in Latin America. Methods: This was a retrospective multicenter study in Argentina, Chile and Mexico. Medical record databases on patients who received ocrelizumab were analyzed. Demographic and clinical variables were described, along with effectiveness outcomes, which included the proportions of patients free from clinical relapses, from disability progression and from new or enlarging T2 or T1 gadolinium-enhancing lesions, on annual magnetic resonance imaging. Results: A total of 81 patients were included. The most frequent phenotype was relapsing-remitting MS, in $64.2 \%$ of the patients. The mean age at study entry was $41.3 \pm 12.0$ years and $51.8 \%$ were women. A total of $38 \%$ had had relapse activity during the 12 months before starting on ocrelizumab, with a mean relapse rate of $1.3 \pm 0.6$ during that period. $75 \%$ were free from clinical relapses and $91 \%$ were free from gadolinium-enhancing lesions in the relapsing-remitting course. Ocrelizumab discontinuation during the first 12 months was
\end{abstract}

\footnotetext{
'Hospital Universitario de CEMIC, Servicio de Neurología, Buenos Aires, Argentina.

${ }^{2}$ Centro de Esclerosis Múltiple de Buenos Aires, Buenos Aires, Argentina.

${ }^{3}$ Hospital Italiano de Buenos Aires, Servicio de Neurología, Buenos Aires, Argentina.

${ }^{4}$ Clínica las Condes, Santiago de Chile, Chile.

Instituto Nacional de Neurología y Neurocirugía, Ciudad de México, México.

${ }^{6}$ Centro Neurológico ABC Santa Fé, Ciudad de México, México.

${ }^{7}$ Hospital Alemán, Department of Neuroscience, Neuroimmunology Unit, Buenos Aires, Argentina.

${ }^{8}$ Clínica Alemana de Santiago, Unidad de Neuroinmunología, Santiago, Región Metropolitana, Chile.

${ }^{9}$ Hospital Ramos Mejía,Centro Universitario de Esclerosis Múltiple, Buenos Aires, Argentina.

${ }^{10}$ Hospital Universitario Sanatorio Guemes, Servicio de Neurología, Buenos Aires, Argentina.
}

Juan Ignacio ROJAS (D) https://orcid.org/0000-0002-9747-3626; Liliana PATRUCCO (D) https://orcid.org/0000-0003-0207-8146;

Manuel FRUNS (D) https://orcid.org/0000-0002-8450-6628; Giesela HORNUNG; José FLORES (D) https://orcid.org/0000-0003-0490-224X; Edgar CARNERO CONTENTTI (D) https://orcid.org/0000-0001-7435-5726; Pablo Adrian LOPEZ (D) https://orcid.org/0000-0002-7705-095X; Juan Pablo PETTINICCHI (D) https:// orcid.org/0000-0002-5770-9243; Alejandro CARIDE (D) https://orcid.org/0000-0001-5228-1404; Lorna GALLEGUILLOS (D) https://orcid.org/0000-00033131-6246; Jorge BARAHONA (iD https://orcid.org/0000-0002-5996-4344; Violeta DIAZ; Marianella HERNÁNDEZ (DD https://orcid.org/0000-0001-7524-3339; Ricardo ALONSO (D) https://orcid.org/0000-0001-9370-2594; Edgardo CRISTIANO (DD https://orcid.org/0000-0002-3751-6217

Correspondence: Juan Ignacio Rojas; E-mail: rojasjuanignacio@gmail.com

Conflicts of interest: EC: has received fees for consultations as a scientific advisory board member and for travel to meetings, conferences and clinical trials of the following companies: Avanir, Bayer, Biogen, Merck, Novartis, Roche and Teva; JIR: has received honoraria from Novartis as a scientific advisor. He has received travel grants and attended courses and conferences on behalf of Merck-Serono Argentina and Novartis Argentina; LP: has received honoraria for scientific and research grants from Teva Tuteur, Merck Serono, Biogen Idec and Bayer Schering; ECC: has received personal compensation for consulting, serving on a scientific advisory board, speaking or other activities with Biogen-Idec, Genzyme, Merck-Serono, Novartis, Teva, Roche and Bayer; PAL: has received personal compensation for consulting, serving on a scientific advisory board, speaking or other activities with Biogen-Idec, Genzyme, MerckSerono, Novartis, Teva, Roche and Bayer; JPP: has received personal compensation for consulting, serving on a scientific advisory board, speaking or other activities with Biogen-Idec, Genzyme, Merck-Serono, Novartis, Teva, Roche and Bayer; AC: has received personal compensation for consulting, serving on a scientific advisory board, speaking or other activities with Biogen-Idec, Genzyme, Merck-Serono, Novartis, Teva, Roche and Bayer; RA: has received personal compensation for consulting, serving on a scientific advisory board, speaking or other activities from Biogen, Merck Serono, Novartis, Sanofi-Genzyme and Roche; MF: has received personal compensation for consulting, serving on a scientific advisory board, speaking or other activities from Biogen, Merck, Novartis and Roche; GH: has received personal compensation for consulting, serving on a scientific advisory board, speaking or other activities from Biogen, Merck, Novartis and Roche; JF, LG, JB, VD and MH: have nothing to disclose.

Authors' contributions: EC: data collection, data management and manuscript review; JIR: data collection, data management, data analysis and manuscript review; LP: data collection, data management and manuscript review; EC, PAL, JPP, AC, RA, MF, GH, JF, LG, JB, VD, MH: data collection and manuscript review. Funding: The research was funded by Roche Latin America.

Received on July 21, 2020; Accepted on August 5, 2020. 
observed in three patients (3.7\%). The mean persistence observed during the first-year follow-up was $338 \pm 24$ days. Conclusions: Our study is in line with previous randomized clinical trials and recent real-world studies describing patient profiles, effectiveness and persistence regarding ocrelizumab treatment in multiple sclerosis patients in Latin America.

Keywords: Multiple Sclerosis; Pharmaceutical Preparations; Latin America; Effective Life.

\section{RESUMEN}

Introducción: A pesar de la abundante información sobre ocrelizumab proveniente de los ensayos clínicos de fase III, todavía se tiene poca evidencia sobre la efectividad y el perfil de pacientes provenientes de la vida real. Objetivo: Evaluar el perfil clínico y demográfico, la efectividad y la persistencia al tratamiento en pacientes que usaron el ocrelizumab para el tratamiento de esclerosis múltiple (EM) en Latinoamérica. Métodos: Estudio retrospectivo multicéntrico en Argentina, Chile y México. Se analizaron los datos de los pacientes que recibieron ocrelizumab. Se describieron las variables demográficas y clínicas, así como los resultados de efectividad que incluyeron la proporción de pacientes libres de recaídas clínicas, libres de progresión de la discapacidad, libres de nuevas lesiones en la secuencia T2 o T1 con gadolinio durante el seguimiento. Resultados: Se incluyeron 81 pacientes. El fenotipo más frecuente fue EM remitente recurrente (EMRR) en el $64,2 \%$ de los pacientes. La edad media fue de $41.3 \pm 12$ años, y el 51,8\% eran mujeres. Un total de $38 \%$ tuvo recaídas durante los 12 meses previos al inicio de ocrelizumab, con una tasa anualizada de recaídas media de $1.3 \pm 0.6$ durante ese período. En el seguimiento a 12 meses, el 75\% estuvo libre de recaídas clínicas y el 91\%, libre de nuevas lesiones en RM. Tres pacientes interrumpieron el tratamiento durante el seguimiento (3,7\%). La persistencia al tratamiento observada durante el primer año de seguimiento fue de $338 \pm 24$ días. Conclusión: Nuestro estudio está en línea con los datos provenientes de ensayos clínicos aleatorizados previos y estudios recientes del mundo real que describen la efectividad de los perfiles de pacientes y la persistencia al tratamiento con ocrelizumab en pacientes con EM en Latinoamérica.

Palabras clave: Esclerosis Múltiple; Preparaciones Farmacéuticas; América Latina; Vida Efectiva.

\section{INTRODUCTION}

Multiple sclerosis (MS) is a chronic inflammatory disease of the CNS that leads to focal plaques of primary demyelination and diffuse neurodegeneration in the grey and white matter of the brain and spinal cord ${ }^{1}$. In most patients, the disease starts with a relapsing-remitting course (RRMS), which is followed for several years by a secondary progressive phase (SPMS). Patients with primary progressive disease (PPMS) skip the relapsing and remitting stage and start with uninterrupted progression from disease onset ${ }^{2}$.

It has been almost 25 years since the publication of the pivotal trial results for the first disease-modifying therapy (DMT) for RRMS ${ }^{3}$. Currently, the DMTs for MS that have been approved by the European Medicines Agency (EMA) and the Food and Drug Administration (FDA) include interferon beta (IFN $\beta$ ) $1 \mathrm{a}$ and $1 b$, glatiramer acetate (GA), mitoxantrone, natalizumab, fingolimod, teriflunomide, dimethyl fumarate, alemtuzumab and ocrelizumab ${ }^{4}$.

Ocrelizumab was approved in March 2017 for the treatment of relapsing or primary progressive MS ${ }^{5}$. A phase II trial established $600 \mathrm{mg}$ intravenously every 6 months as the preferred dosing schedule. Two phase III trials evaluated the efficacy of ocrelizumab in patients with RRMS and individual and pooled analyses demonstrated significant reductions in the annualized relapse rate $(\mathrm{p}<0.001$ pooled), disability progression at 12 weeks ( $\mathrm{p}<0.001$ pooled) and gadolinium-enhancing lesions on magnetic resonance imaging (MRI; $\mathrm{p}<0.001)^{5}$. Patients with PPMS were evaluated in a third phase III trial, which showed a significant decrease in both disease progression at 12 weeks $(p=0.03)$ and the volume of T2-weighted lesions on MRI $(\mathrm{p}<0.001)^{5}$. As with other monoclonal antibodies, the adverse effects seen with ocrelizumab were primarily infusion-related reactions and infection ${ }^{5}$. Despite the abundance of information concerning the efficacy and safety of ocrelizumab in phase III clinical trials, there is scarce evidence regarding realworld patient profiles.

The aim of this study was therefore to evaluate patient profiles, effectiveness and persistence with treatment during follow-up, in a retrospective study on patients who were prescribed ocrelizumab for treatment of MS in Latin America (LATAM).

\section{METHODS}

We conducted a retrospective multicenter study in Argentina, Chile and Mexico. We reviewed all medical record databases of patients who received ocrelizumab and were followed for at least one year before and after starting treatment. Only patients with a diagnosis of MS defined according to validated criteria were considered for inclusion in the study ${ }^{6,7}$.

\section{Clinical parameters evaluated at baseline}

The demographic and clinical characteristics of the disease were collected at the time when use of ocrelizumab was started. Age and gender data were extracted, along with disease characteristics including the following: age at onset, disease duration since the first relapse (defined as detection of the first sign/symptom that suggested CNS demyelination in the optic nerves, brain stem, spinal cord or other regions and which was not attributable to other diseases ${ }^{8}$ ), clinical and radiological activity during the year previous to ocrelizumab treatment (clinical activity defined as new 
relapse and radiological activity, such as new T2 or GAD MRI lesions), number of relapses, EDSS score (pre-treatment), prior exposure to DMTs and reasons for change of treatment to ocrelizumab.

\section{Follow-up evaluation}

Once ocrelizumab had been started, the patients were followed for at least 12 months for the analysis. Clinical evaluations every three months tended to collect information about the following three matters: a) Clinical relapses. These were defined as the appearance of a new neurological symptom that lasted more than 24 hours, in the absence of clinical intercurrence, followed by a period of clinical stability or improvement of at least 30 days. b) Progression of physical disability. This was evaluated through clinical evaluation by applying the EDSS scale. This variable was dichotomized for analysis, into patients who progressed in EDSS and patients who did not progress. Progression was defined as a worsening of 1 point on the scale between one measurement and another, with an interval of at least 6 months between them. To consider a case to be one of progression, if there had been a clinical relapse, the patient needed to be 3 months away from the relapse, regardless of whether steroid treatment had been received for management of the acute episode. c) New lesions found on MRI. MRI was done using 1.5 tesla equipment, with slices of thickness 3 to $5 \mathrm{~mm}$. The sequences obtained were T1, T2, FLAIR and T1 with intravenous contrast. MRI scans were obtained at baseline and at 12 months, on each patient.

\section{Persistence evaluation}

Information from the patients was collected for at least 12 months after use of ocrelizumab was started. During the follow-up, the proportion of patients discontinuing the treatment with ocrelizumab over the 12 months after inclusion and the reasons for discontinuation were registered. These reasons were categorized into four groups: 1) poor tolerability, i.e. when discontinuation was 'patient driven' due to side effects; 2) adverse events, i.e. when discontinuation was 'physician-driven' due to medical concerns regarding expected or unexpected side effects; 3) disease activity, i.e. radiological or clinical events that led physicians to discontinue treatment because of lack of efficacy; and 4) others, i.e. any reason not included in the previous definitions.

\section{Storage and data analysis}

Once patients had been identified and had consented to participate, variables from the patient charts were transferred to the specifically designed web platform, with restricted access by users and a password specific to each researcher. The data shared were anonymized and only demographic and clinical data were accessible. Patient data such as name, surname and ID were not visible to the analysts.
The study was approved by the local ethics committee of each participating center, and written or oral informed consent was obtained from all participants.

\section{Statistical analysis}

Continuous data were expressed with their means and SD. Categorical data were expressed as percentages. Demographic and clinical variables were described, along with the proportion of the patients who discontinued the treatment with ocrelizumab over the 12 months after inclusion. Persistence was a continuous value defined as the number of days from the date of starting ocrelizumab use to the date of discontinuation of the index treatment. Statistical analyses were performed using the Stata 15 software.

\section{RESULTS}

\section{Study population and baseline characteristics}

A total of 81 patients met the inclusion criteria and were included (38.3\% were from Argentina, 40.7\% from Chile and $21 \%$ from Mexico) (Table 1). Many of the patients included were part of the compassionate use of ocrelizumab in Latin America. The most frequent phenotype was RRMS, in $64.2 \%$ of the patients included (Table 1). The mean age of the patients at study entry was $41.3 \pm 12.0$ years, and $51.8 \%$ of the patients were women. The mean disease duration was 8.4 years, and most of the patients included were in employment at the time of study entry (77\%). The principal characteristics of the patients included are presented in Table 2. The main reason for starting ocrelizumab among RRMS patients was treatment failure, in $48 \%$, while among PPMS patients the most frequent reason was disease progression (defined as EDSS progression).

A total of $38 \%$ of the patients included had had relapse activity during the 12 months before starting use of ocrelizumab. During that period, the mean relapse rate was $1.3 \pm 0.6$. Almost all the relapses in the cohort were treated with corticosteroids (96\%). EDSS progression was observed in $49.4 \%$ of patients during the previous 12 months, while new T2 MRI lesions were described in $68 \%$ of the patients. The activity during the 12 months before use of ocrelizumab was started is described in Table 3.

Table 1. Patient distribution according to country and disease phenotype.

\begin{tabular}{lccc}
\hline & Total & RRMS & PPMS \\
\hline Argentina, $\mathrm{n}(\%)$ & $31(38.3)$ & $5(16.1)$ & $26(83.9)$ \\
Chile, $\mathrm{n}(\%)$ & $33(40.7)$ & $30(90.9)$ & $3(9.1)$ \\
Mexico, $\mathrm{n}(\%)$ & $17(21.0)$ & $17(100)$ & 0 \\
Total, $\mathrm{n}(\%)$ & $81(100)$ & $52(64.2)$ & $29(35.8)$ \\
\hline
\end{tabular}

RRMS: relapsing-remitting multiple sclerosis; PPMS: primary progressive multiple sclerosis. 


\section{Effectiveness}

Among RRMS patients, during the follow-up, $15 \%$ had a relapse, $4 \%$ progressed in EDSS and 8\% had new gadolinium lesions on follow-up MRI (Table 3). Among PPMS patients, $7 \%$ had a relapse, $31 \%$ progressed in EDSS and only 2 patients had a new gadolinium lesion on MRI during follow-up (Table 3). Among both RRMS and PPMS patients, there was a

Table 2. Patient characteristics at baseline.

\begin{tabular}{|c|c|c|c|}
\hline & Total & RRMS & PPMS \\
\hline Mean age (years) $\pm S D$ & $41.3 \pm 12.0$ & $37.8 \pm 12.0$ & $47.4 \pm 12.0$ \\
\hline Female sex, n (\%) & $42(51.8)$ & $31(60)$ & $11(38)$ \\
\hline Mean EDSS $\pm S D$ & $3.1 \pm 1.8$ & $2.8 \pm 1.9$ & $3.6 \pm 1.7$ \\
\hline $\begin{array}{l}\text { Mean disease duration } \\
\text { (years) } \pm S D\end{array}$ & $8.4 \pm 6.3$ & $8.8 \pm 7.2$ & $7.8 \pm 4.3$ \\
\hline \multicolumn{4}{|l|}{ Working status } \\
\hline Employed & $63(77)$ & $40(77)$ & $23(79)$ \\
\hline Unemployed & $18(23)$ & $12(23)$ & $6(21)$ \\
\hline Previous DMT, n (\%) & $62(76.5)$ & $45(86)$ & $17(58)$ \\
\hline \multicolumn{4}{|l|}{ Type of previous DMT, n (\%) } \\
\hline Beta interferon & $23(37.0)$ & $16(35.5)$ & $7(41.0)$ \\
\hline Glatiramer acetate & $2(3.2)$ & $2(4.5)$ & 0 \\
\hline Teriflunomide & $1(1.6)$ & $1(2.2)$ & 0 \\
\hline Fingolimod & $5(8.0)$ & $2(4.5)$ & $3(17.7)$ \\
\hline Dimethyl fumarate & $1(1.6)$ & $1(2.2)$ & 0 \\
\hline Natalizumab & $14(22.5)$ & $11(24.5)$ & $3(17.7)$ \\
\hline Rituximab & $16(25.8)$ & $12(26.7)$ & $4(23.5)$ \\
\hline $\begin{array}{l}\text { Previous } 2 \text { or more DMT, } \\
\mathrm{n}(\%)\end{array}$ & $41(50)$ & $32(61)$ & $9(31)$ \\
\hline \multicolumn{4}{|c|}{ Reason for starting use of ocrelizumab } \\
\hline $\begin{array}{l}\text { Treatment failure } \\
\text { with previous DMT }\end{array}$ & $20(25)$ & $25(48)$ & $6(21)$ \\
\hline $\begin{array}{l}\text { Adverse event with } \\
\text { previous DMT }\end{array}$ & $31(38)$ & $14(27)$ & $6(21)$ \\
\hline Disease progression & $30(37)$ & $13(25)$ & $17(58)$ \\
\hline
\end{tabular}

RRMS: relapsing-remitting multiple sclerosis; PPMS: primary progressive multiple sclerosis; EDSS: expanded disability status scale; DMT: diseasemodifying treatment; SD: standard deviation. reduction in the annualized relapse rate, in comparison with the year before ocrelizumab treatment was started (1.4 \pm 0.7 vs. $0.23 \pm 0.4 ; p<0.001$; and $1 \pm 0.3$ vs. $0.22 \pm 0.15 ; p=0.01$; in RRMS and PPMS respectively) (Table 3 ).

\section{Persistence evaluation}

Regarding ocrelizumab administration and persistence during the first year of ocrelizumab treatment, the mean time between the first administration (300 mg) and the second administration (corresponding to the first cycle) was 16 days, while the period between the first and the second cycles was 6.1 months. Ocrelizumab discontinuation during the first 12 months was observed in 3 patients (3.7\%). The reasons are described in Table 4. The mean persistence observed at the time of the first-year follow-up was $338 \pm 24$ days (Figure 1).

Table 4. Persistence with ocrelizumab use during the 12 months of follow-up.

\begin{tabular}{|c|c|c|c|}
\hline & Total & RRMS & PPMS \\
\hline $\begin{array}{l}\text { Mean number of } \\
\text { ocrelizumab cycles, } n \pm S D\end{array}$ & $3.6 \pm 0.62$ & $3.6 \pm 0.5$ & $3.5 \pm 0.82$ \\
\hline $\begin{array}{l}\text { Days between first and } \\
\text { second applications, } \\
\text { mean } \pm S D\end{array}$ & $16.0 \pm 2.6$ & $16.3 \pm 2.9$ & $16.8 \pm 3.1$ \\
\hline $\begin{array}{l}\text { Months between first and } \\
\text { second cycles, mean } \pm \text { SD }\end{array}$ & $6.1 \pm 0.6$ & $6.1 \pm 0.7$ & $6.2 \pm 0.77$ \\
\hline $\begin{array}{l}\text { Months between second } \\
\text { and third cycles, mean } \\
\pm \text { SD }\end{array}$ & $6.5 \pm 0.84$ & $6.5 \pm 0.81$ & $6.6 \pm 0.91$ \\
\hline $\begin{array}{l}\text { Months between third } \\
\text { and fourth cycles, mean } \\
\pm \mathrm{SD}\end{array}$ & $7.1 \pm 0.9$ & $6.4 \pm 0.8$ & $7.3 \pm 0.95$ \\
\hline $\begin{array}{l}\text { Ocrelizumab } \\
\text { discontinuation, n (\%) }\end{array}$ & $3(3.7)$ & $1(1.9)$ & $2(6.7)$ \\
\hline \multicolumn{4}{|l|}{ Reason for discontinuation } \\
\hline Poor tolerability & $1(33.3)$ & 0 & $1(50)$ \\
\hline Disease activity & $1(33.3)$ & 0 & $1(50)$ \\
\hline Other & $1(33.3)$ & $1(100)$ & 0 \\
\hline
\end{tabular}

RRMS: relapsing-remitting multiple sclerosis; PPMS: primary progressive multiple sclerosis; SD: standard deviation.

Table 3. Patient characteristics before and after starting treatment with ocrelizumab.

\begin{tabular}{|c|c|c|c|c|c|c|}
\hline & \multicolumn{3}{|c|}{ RRMS } & \multicolumn{3}{|c|}{ PPMS } \\
\hline & $\begin{array}{l}\text { Year before } \\
\text { treatment with } \\
\text { ocrelizumab }\end{array}$ & $\begin{array}{l}\text { After starting } \\
\text { treatment with } \\
\text { ocrelizumab }\end{array}$ & $\mathrm{p}$-value & $\begin{array}{l}\text { Year before } \\
\text { treatment with } \\
\text { ocrelizumab }\end{array}$ & $\begin{array}{l}\text { After starting } \\
\text { treatment with } \\
\text { ocrelizumab }\end{array}$ & $p$-value \\
\hline Relapse activity, n (\%) & $32(62)$ & $8(15)$ & 0.01 & $11(38)$ & $2(7)$ & 0.37 \\
\hline Mean relapse rate $\pm \mathrm{SD}$ & $1.4 \pm 0.7$ & $0.23 \pm 0.4$ & $<0.001$ & $1 \pm 0.3$ & $0.22 \pm 0.15$ & 0.01 \\
\hline Steroid treatment for relapse, $\mathrm{n}(\%)$ & $30(95)$ & $3(37)$ & 0.001 & $9(100)$ & $2(100)$ & 0.67 \\
\hline EDSS progression, $n(\%)$ & $21(40.4)$ & $2(4)$ & 0.31 & $19(65.5)$ & $9(31)$ & 0.09 \\
\hline GAD + MRI activity, $n(\%)$ & $30(58.0)$ & $4(8)$ & 0.06 & $10(34.5)$ & $2(7)$ & 0.44 \\
\hline T2 MRI activity, $\mathrm{n}(\%)$ & $41(78.8)$ & $18(35)$ & 0.001 & $19(65.5)$ & $7(24)$ & 0.05 \\
\hline
\end{tabular}

RRMS: relapsing-remitting multiple sclerosis; PPMS: primary progressive multiple sclerosis; SD: standard deviation; GAD, MRI and T2: types of lesions. 


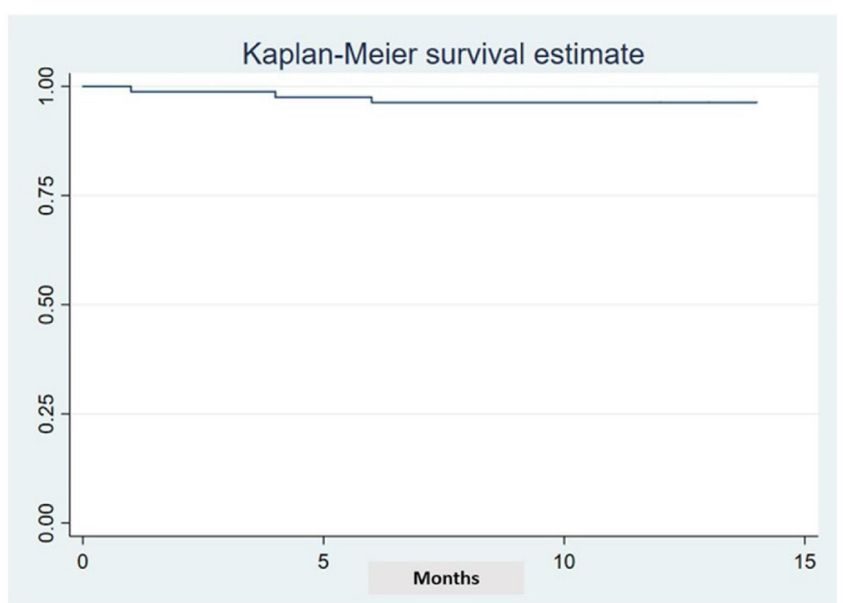

Figure 1. Persistence with ocrelizumab treatment during the study period.

\section{DISCUSSION}

The aim of this study was to describe patient profiles, effectiveness and persistence regarding ocrelizumab treatment in MS patients in Latin America. We analyzed 81 patients at three centers in Argentina, two centers in Chile and one center in Mexico. The most frequent phenotype was RRMS, in $64.2 \%$ of the patients included. The main reason for starting use of ocrelizumab among RRMS patients was treatment failure (in 48\%), while among PPMS patients the most frequent reason was disease progression (defined as EDSS progression). EDSS progression had been observed in $49.4 \%$ of the patients during the previous 12 months, while new T2 MRI lesions were described in $68 \%$ of the patients. Among both RRMS and PPMS patients, there were reductions in the annualized relapse rate, comparing the year before and the year after ocrelizumab treatment was started. Ocrelizumab discontinuation during the first 12 months was observed in 3 patients, while $96.3 \%$ of the patients were continuing the treatment after 12 months of follow-up.

The results from our study are in line with previous randomized clinical trials and recent real-world studies. In OPERA I, OPERA II and ORATORIO, the patient profiles for RRMS and PPMS were not different from those described in our study, in terms of age, gender distribution and disease duration. Regarding adverse events leading to treatment discontinuation during 96 weeks of follow-up, these were observed in 3.2\% of the patients in OPERA I, while in OPERA II discontinuation was observed in $3.8 \%$ of the patients in the ocrelizumab arm. This rate was similar to the frequency observed in our study 9 . In the ORATORIO trial, the proportion of the patients in the ocrelizumab arm who discontinued the treatment due to adverse events was reported to be $4.1 \%$ after two years of follow-up ${ }^{10}$.

Our study has certain limitations. One important weakness was the low number of patients recruited. Although a greater number of patients could have given a different power to the study, our number permitted the intended analysis. Another limitation was the observational design and the lack of randomization and control group. Lastly, there was only a short follow-up (up to one year).

Our results nevertheless represent the first post-marketing studies conducted in Latin America and in its region, on the use of ocrelizumab in a real-world setting. The importance of this study lies in the possibility that it has provided for exploring other conditions beyond the efficacy and safety of specific treatments, in large populations of patients that are not typically included in initial randomized controlled trials, thereby improving our knowledge about a specific treatment in clinical practice ${ }^{11,12}$.

\section{References}

1. Mahad DH, Trapp BD, Lassmann H. Pathological mechanisms in progressive multiple sclerosis. Lancet Neurol. 2015 Feb;14(2):18393. https://doi.org/10.1016/s1474-4422(14)70256-x

2. Comi G, Radaelli M, Soelberg Sorensen P. Evolving concepts in the treatment of relapsing multiple sclerosis. Lancet. 2017 Apr;389(10076):1347-56. https://doi.org/10.1016/s0140-6736(16)32388-1

3. Interferon beta- $1 \mathrm{~b}$ is effective in relapsing-remitting multiple sclerosis. I. Clinical results of a multicenter, randomized, double-blind, placebocontrolled trial. The IFNB Multiple Sclerosis Study Group. Neurology. 1993 Apr;43(4):655-61. https://doi.org/10.1212/wnl.43.4.655

4. Soelberg Sorensen P, Giovannoni G, Montalban X, Thalheim C, Zaratin P, Comi G. The Multiple Sclerosis Care Unit. Mult Scler. 2019 Apr;25(5):627-36. https://doi.org/10.1177/1352458518807082

5. Stahnke AM, Holt KM. Ocrelizumab: A New B-cell Therapy for Relapsing Remitting and Primary Progressive Multiple Sclerosis. Ann Pharmacother. 2018 May;52(5):473-83. https://doi.org/10.1177/1060028017747635

6. Thompson AJ, Banwell BL, Barkhof F, Carroll WM, Coetzee T, Comi $G$, et al. Diagnosis of multiple sclerosis: 2017 revisions of the McDonald criteria. Lancet Neurol. 2018 Feb;17(2):162-73. https://doi. org/10.1016/s1474-4422(17)30470-2

7. Polman $\mathrm{CH}$, Reingold SC, Banwell B, Clanet M, Cohen JA, Filippi M, et al. Diagnostic criteria for multiple sclerosis: 2010 revisions to the
McDonald criteria. Ann Neurol. 2011 Feb;69(2):292-302. https://doi. org/10.1002/ana.22366

8. Miller D, Barkhof F, Montalban X, Thompson A, Filippi M. Clinically isolated syndromes suggestive of multiple sclerosis, part I: natural history, pathogenesis, diagnosis, and prognosis. Lancet Neurol. 2005 May;4(5):281-8. https://doi.org/10.1016/s14744422(05)70071-5

9. Hauser SL, Bar-Or A, Comi G, Giovannoni G, Hartung HP, Hemmer B, et al. Ocrelizumab versus Interferon Beta-1a in Relapsing Multiple Sclerosis. N Engl J Med. 2017 Jan;376(3):221-34. https://doi. org/10.1056/nejmoa1601277

10. Montalban X, Hauser SL, Kappos L, Arnold DL, Bar-Or A, Comi G, et al. Ocrelizumab versus Placebo in Primary Progressive Multiple Sclerosis. N Engl J Med. 2017 Jan;376(3):209-20. https://doi. org/10.1056/nejmoa1606468

11. Trojano M, Tintore M, Montalban X, Hillert J, Kalincik T, laffaldano P, et al. Treatment decisions in multiple sclerosis - insights from realworld observational studies. Nat Rev Neurol. 2017 Feb;13(2):105-18. https://doi.org/10.1038/nrneurol.2016.188

12. Kalincik T. Effectiveness of oral multiple sclerosis therapies in clinical context. Neurology. 2019 Apr;92(16):737-8. https://doi. org/10.1212/wnl.0000000000007300 